\title{
Passage of digesta through the intestines of the sheep
}

Retention times in the small and large intestines

\author{
By J. B. COOMBE* AND R. N. B. KAY \\ Rowett Research Institute, Bucksburn, Aberdeen \\ (Received 24 September I964-Accepted 21 April 1965)
}

In studies on the rate of passage of food through the alimentary tract of the ruminant, most workers have examined the gut as a whole or have differentiated only between the reticulo-rumen and the remainder of the gut (Balch, I950; Castle, I956a, $b$; Blaxter, Graham \& Wainman, I956). This is no doubt due to the emphasis rightly placed on digestion in the reticulo-rumen, which usually holds about $70 \%$ of the total gut contents. It is generally accepted that passage of digesta through the intestines is fairly rapid compared with passage through the reticulo-rumen, and that once digesta leave the stomach they are propelled by peristaltic contractions.

Although the volatile fatty acids absorbed from the compartments of the stomach satisfy most of the energy requirements of ruminants, most nitrogenous compounds other than ammonia, lipids other than volatile fatty acids, vitamins and a little carbohydrate are absorbed from the small intestine, and both small and large intestines share in the absorption of large amounts of water and minerals; in addition a small amount of organic matter is digested in the large intestine (Boyne, Campbell, Davidson \& Cuthbertson, 1956; Hogan \& Phillipson, 1960; van Weerden, 1961 ; Hydén, 1961 $a$; Smith, I962; Goodall \& Kay, 1965). The efficiency with which these functions are performed may be influenced by the time that the digesta remain in the intestines, and so it was considered that there was a need for a more thorough knowledge of the factors which affect the intestinal flow.

This paper describes experiments carried out with three fistulated sheep to study the relation between diet and retention times in the small and large intestines, separately or together. The term 'retention time' refers to the mean time taken by digesta or a marker substance to pass through a specified section of the gut, and it is the reciprocal of the mean rate of passage.

\section{EXPERIMENTAL}

\section{Animals and their treatment}

Three Scottish Blackface sheep were used in these experiments; Alfred (33 kg) and Charlie ( $39 \mathrm{~kg}$ ) were wethers and Clara $(47 \mathrm{~kg}$ ) was a ewe. All were about 3 years old. Alfred and Clara had previously been used in experiments described by Goodall \& Kay (1965). Each sheep was fitted with a Perspex cannula of $\mathrm{I} \mathrm{cm}$ internal diam. in the duodenum, and had re-entrant plastic cannulas (Ash, 1962) inserted into the

* Present address: Division of Plant Industry, CSIRO, Canberra, Australia. 
terminal ileum as described by Goodall $\&$ Kay (1965). These re-entrant cannulas formed an external loop through which all the digesta flowed. Charlie also had an ebonite rumen cannula. All operations were done at least 3 months before the experiments began. Unfortunately after two experiments the proximal ileal fistula in Clara began to leak badly and the sheep had to be destroyed.

Table I. Composition of the foods

\begin{tabular}{|c|c|c|c|c|c|c|}
\hline & Dry & $\begin{array}{l}\text { Crude } \\
\text { protein }\end{array}$ & $\begin{array}{l}\text { Crude } \\
\text { fibre }\end{array}$ & $\begin{array}{l}\text { Ether } \\
\text { extract }\end{array}$ & $\begin{array}{l}\text { Nitrogen- } \\
\text { free } \\
\text { extract }\end{array}$ & Ash \\
\hline Food & $(\%)$ & \multicolumn{5}{|c|}{ ( $\%$ of dry matter) } \\
\hline $\begin{array}{l}\text { Dried grass } \\
\text { Hay }\end{array}$ & $\begin{array}{l}83 \cdot 8 \\
80 \cdot 1\end{array}$ & $\begin{array}{r}15 \cdot 0 \\
8 \cdot 0\end{array}$ & $\begin{array}{l}24 \cdot 9 \\
33 \cdot 3\end{array}$ & $\begin{array}{l}2 \cdot 7 \\
1 \cdot 5\end{array}$ & $\begin{array}{l}49^{\circ} 0 \\
5 I^{\prime} \cdot I\end{array}$ & $\begin{array}{l}8.4 \\
6 \cdot 1\end{array}$ \\
\hline
\end{tabular}

During experimental periods the sheep were housed in metal metabolism cages of the type described by Duthie (1959). Water was freely available. The diets consisted of either meadow hay or dried grass, chopped to 3 in. lengths. Their composition is shown in Table $\mathrm{x}$. The sheep were fed at 8.30 am and $4 \mathrm{pm}$, and always finished their meal within $\mathrm{I} \frac{1}{2} \mathrm{~h}$. Half the ration was offered at each time. Any uneaten food was collected and weighed daily and dried at $105^{\circ}$ for $48 \mathrm{~h}$. The amounts of each diet, the faecal output and the digestibility of the diet are shown in Table 2, together with details of the measurements of retention time. Each experimental period consisted of a 1o-day preliminary period, followed by to days during which faeces were collected daily, weighed and dried at $105^{\circ}$ for $48 \mathrm{~h}$. Measurements of intestinal retention times were made after this second period.

\section{Measurement of retention times}

Introduction of markers. In order to measure the retention time of food residues in the small and large intestines, markers were introduced by way of the duodenal cannula and recovered in the faeces. For measurements of retention time in the small intestine alone the markers were introduced into the duodenum and recovered by collection of the digesta flowing through the ileal cannulas, and for the large intestine alone the markers were introduced into the distal ileal cannula and recovered in the faeces.

Measurements of retention times in the small and large intestines together and in the large intestine alone were usually made concurrently by introducing different coloured markers into the duodenum and terminal ileum at the same time. In addition, polyethylene glycol (PEG) (see below) was introduced at only one of the sites. Faeces were then collected automatically for the following $56 \mathrm{~h}$ by attaching a narrow shute to the bottom of the faeces screen so as to direct the faeces into plastic bags, twentyfour of which were attached to the rim of a sample collector. This rotated once in $24 \mathrm{~h}$ and so took hourly collections of faeces.

Three different markers were used:

(r) Small, flexible discs, about $3 \mathrm{~mm}$ diam. and 0.10 to $0.15 \mathrm{~mm}$ thick, punched from coloured polyvinyl chloride sheeting with a cork-borer; (2) particles of straw, 
Vol. 19

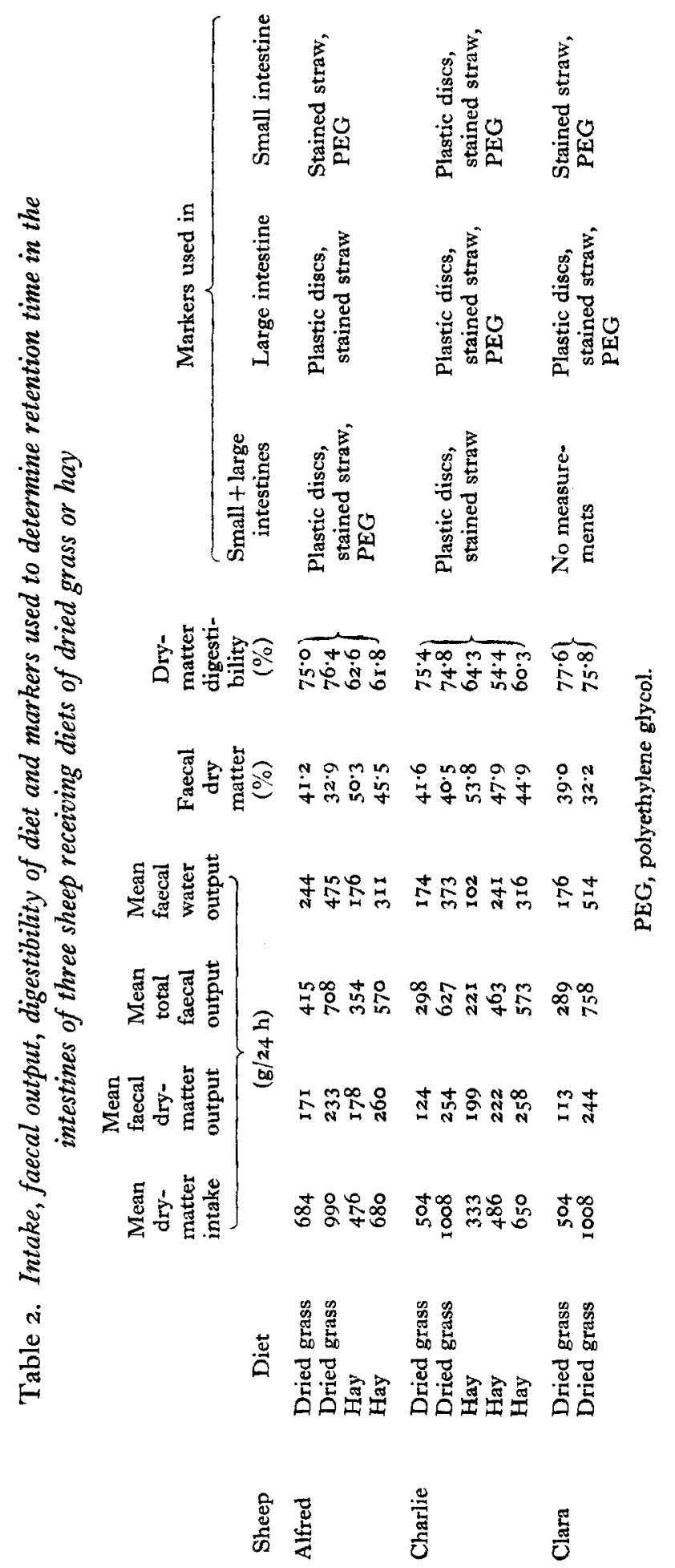


milled to pass a $0.8 \mathrm{~mm}$ screen, and stained with either brilliant green or basic fuchsine; (3) PEG.

The amounts of markers used were Ioo plastic discs, I g stained straw and 2 g PEG. For measurements of retention in the small intestine alone half these amounts of all three markers were introduced into the distal duodenal cannula. Digesta were first collected from the ileal cannulas immediately after the markers had been introduced and the collection was continued for the next $6-7 \mathrm{~h}$. The collection was made by disconnecting the two ileal cannulas and conducting the flow of digesta from the proximal cannula into numbered $50 \mathrm{ml}$ tubes. When each tube was nearly full, the weight of digesta collected and the time were recorded, and an equal amount of digesta, collected previously from a donor sheep receiving the same diet, was poured into a funnel leading to the distal ileal cannula.

The markers were always introduced between 10.00 and $10.30 \mathrm{am}$, which gencrally was about half an hour after the sheep had finished eating. The plastic discs were introduced first, followed immediately by the other markers suspended in either $25 \mathrm{ml}$ of duodenal digesta or $40 \mathrm{ml}$ of ileal digesta, collected previously. About $10 \mathrm{ml}$ of $0.9 \%(\mathrm{w} / \mathrm{v}) \mathrm{NaCl}$ solution were used to wash in the last traces of marker.

Estimation of markers. Each faecal collection was weighed and the pellets were broken in a macerator. About $10 \%$ of the macerated faeces was then shaken on a sieve of zinc sheeting perforated with holes $2 \mathrm{~mm}$ in diam. to remove the plastic discs and was then weighed and dried at $105^{\circ}$ for $48 \mathrm{~h}$ to determine its dry-matter content. The remaining $90 \%$ of the collection was weighed and macerated with water, and the resulting suspension was made up to a volume of either 500 or $1000 \mathrm{ml}$ with water. From this suspension, duplicate $25 \mathrm{ml}$ samples were centrifuged at $2000 \mathrm{~g}$ for 10 min. The sediment from each duplicate was re-suspended in 100 or $200 \mathrm{ml}$ of water, twenty drops of the suspensions were examined separately under $\times 10$ magnification and the number of stained particles present in the twenty drops was recorded. From a knowledge of the volume of forty drops, the total number of stained particles in the original faeces collection was calculated. The supernatant fluid from the centrifugation was kept for determination of PEG by the method of Hydén (1955). The remainder of the faeces suspension, and the suspensions used for counting stained particles, were all passed through the sieve after the completion of these other analyses so that the total number of plastic discs present in the original faeces collection could be counted.

Ileal digesta were analysed in a similar manner. About $10 \%$ of each collection was used for a dry-matter determination by drying at $105^{\circ}$ for $48 \mathrm{~h}$. The remainder was weighed again, diluted to $100, x^{\circ}$ or $200 \mathrm{ml}$ with water, and duplicate $25 \mathrm{ml}$ portions were analysed for stained particles and PEG as described above. The plastic discs in each collection were counted by passing the suspensions through the sieve, together with the broken crust from the dry-matter determination.

Calculation of retention time. Two methods were used. The first recorded excretion of markers against time. It was necessary to assume that each faeces collection was excreted half way through the hourly period concerned, since the exact time of defaecation was not known. The length of time between dosing and excretion in the 
faeces ( $T$ ) was multiplied by the total amount of marker $(M)$ in that collection (number of stained particles, number of plastic discs or $\mathrm{mg}$ of $\mathrm{PEG}$ ) and the mean retention time was given by $\Sigma M T / \Sigma M$. 'The mean retention time calculated in this way should, in principle, be much the same as the mean retention time ' $R$ ' calculated by Castle (1956a). The same method was used for the calculation of mean retention times in the small intestine, though here the exact time of each ileal flow was known.

The second method recorded excretion of markers against cumulative excretion of dry matter in the faeces (F) from the time of dosing. The expression $\Sigma M F / \Sigma M$ gives the cumulative dry-matter output corresponding to the excretion of the 'average' particle. This was then converted into time, using the average faecal dry-matter output per $24 \mathrm{~h}$ calculated from collections made during the 14 days before and during the experiment. The same method was applied to the small intestine, using the average hourly rate of dry-matter output over the collection period.

When the values obtained by each method were compared, only with the large intestine was there any difference; here use of cumulative dry-matter output gave the longer retention time, but the difference was not statistically significant. The results given below have been calculated by the second method, since it was thought that this would tend to eliminate variations in mean retention time caused simply by chance variations in defaecation or ileal flow.

Statistical methods were based on Snedecor (1956).

\section{RESULTS}

\section{Retention time and diet}

Table 3 presents the mean retention times of each marker for the three sheep used. Three main conclusions stand out. First, the markers were retained many times longer in the large intestine, $10 \cdot 2-26 \cdot 5 \mathrm{~h}$, than in the small intestine, $2 \cdot 25-4 \cdot 50 \mathrm{~h}$. Second, the greater the intake of a particular food, the shorter was the retention time. Exceptions to this rule were found with Charlie. Third, the markers were retained for the shortest time when the less digestible food, hay, was eaten.

The statistical significance of these results is shown in Table 4, in which the retention times for all three markers have been averaged. Differences between sheep were generally small and inconsistent.

In those experiments in which the same marker was used to measure retention times in the small and large intestines, both separately and together, it was possible to estimate retention time in either the small or large intestine either directly or by difference. There was no significant difference between the values derived by the two methods.

Correlations. Various correlations were calculated on a within-animal, within-diet basis in an attempt to determine which factors were most closely related to the retention of stained particles in the intestines. These are shown in Table 5. Results for Clara were omitted from these calculations. The factors studied in relation to retention time were dry-matter intake, faeces wet weight, dry weight and water, and faecal dry-matter concentration.

Retention times in the small and large intestines together and in the large intestine 


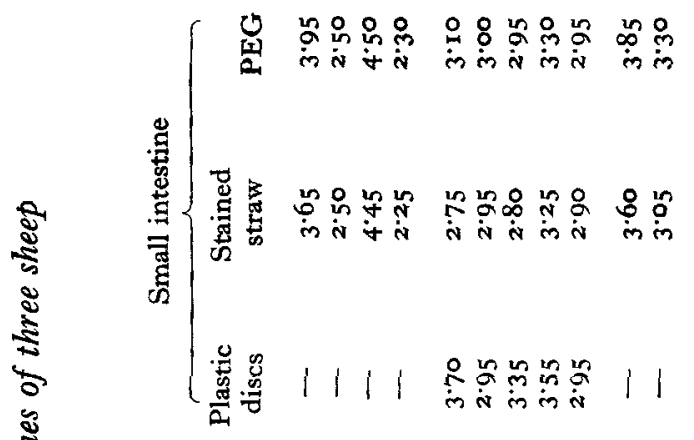


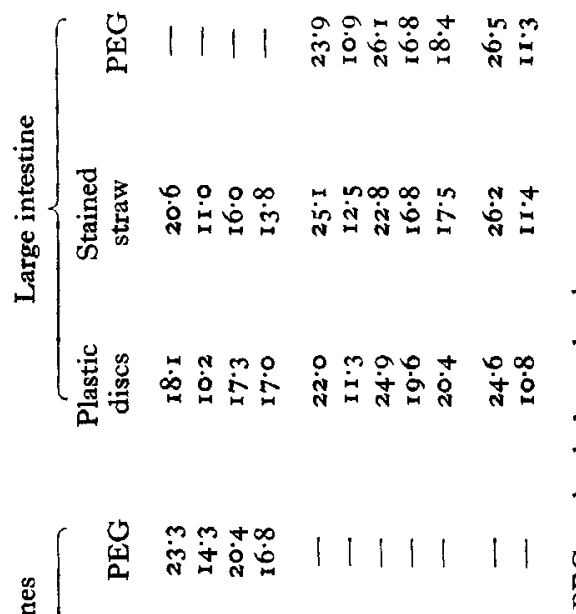

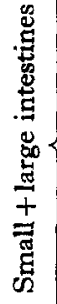

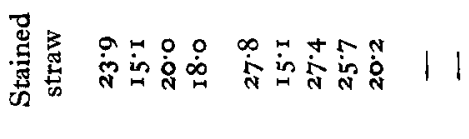

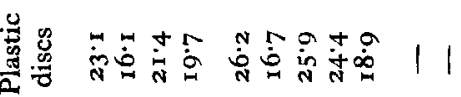

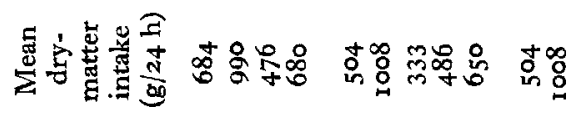

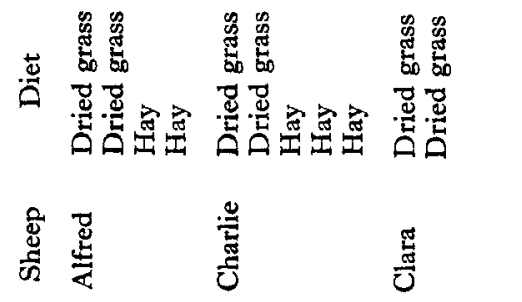


Vol. 19

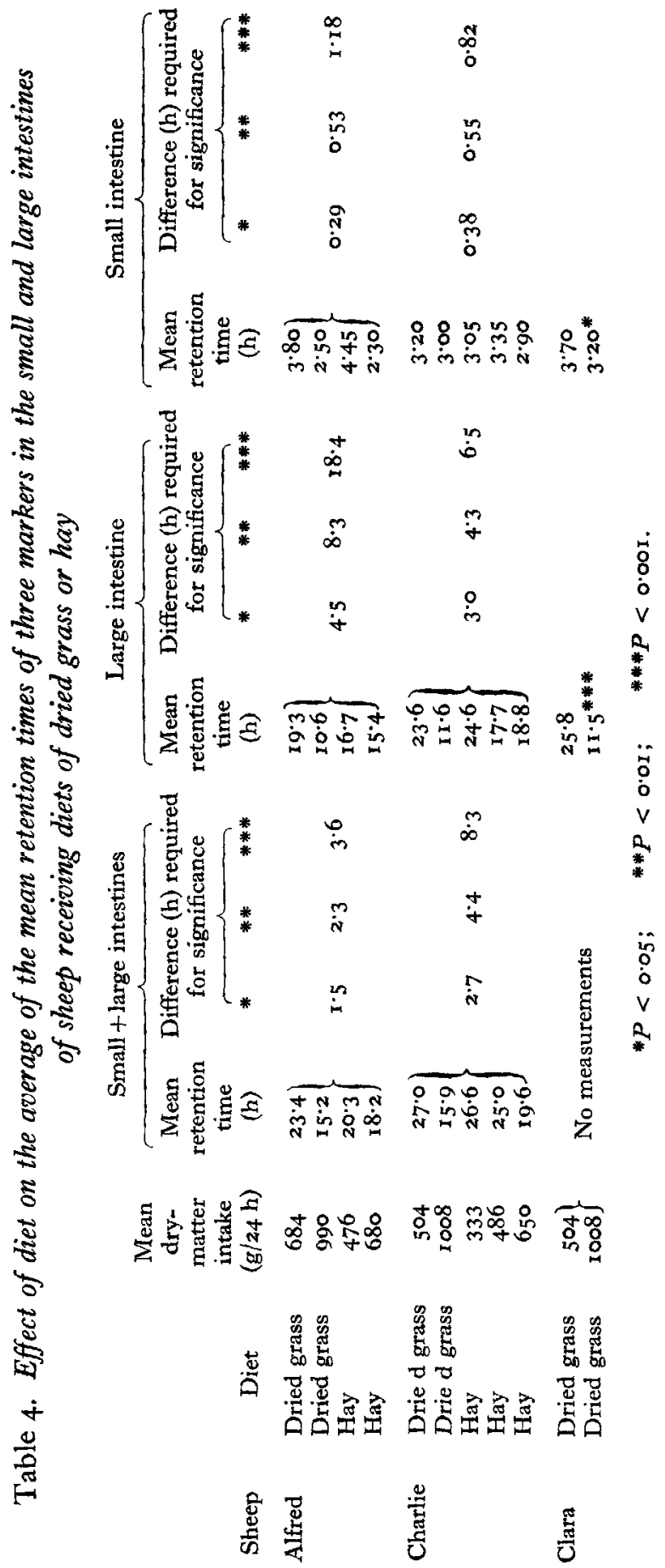


alone correlated about equally well with dry-matter intake and with all measures of faecal output, so that it is not possible to identify which of these factors had most bearing on retention time. Similar relationships were found in the small intestine but they did not achieve statistical significance. The percentage of dry matter in the faeces only correlated moderately well with intestinal retention times.

\section{Table 5. Correlations of various factors with mean retention time for stained straw} in the intestines of two sheep receiving diets of dried grass or hay

\begin{tabular}{lccc}
\multicolumn{1}{c}{ Factor } & Small intestine & Large intestine & Small + large intestincs \\
Dry-matter intake & -0.55 & $-0.93^{* *}$ & $-0.98^{* * *}$ \\
Total faecal output & -0.60 & $-0.91^{*}$ & $-0.92^{* *}$ \\
Faecal dry-matter output & -0.51 & $-0.87^{*}$ & $-0.87^{*}$ \\
Faecal water output & -0.63 & $-0.90^{*}$ & $-0.92^{* *}$ \\
Faecal dry matter $(\%)$ & +0.65 & +0.69 & +0.71 \\
$\qquad P<0.05 ;$ & $* * P<0.01 ;$ & $* * * P<0.001$. &
\end{tabular}

\section{Differences between markers}

To establish possible differences in the retention times of the different markers, the values for the three sheep were considered together whenever possible and the differences between markers were analysed by the $t$ test or analysis of variance of paired estimates. These comparisons showed that PEG had a slightly, but significantly $(P<0.01)$, higher mean retention time in the small intestine than did particles of stained straw. No other differences were apparent.

\section{Patterns of excretion}

The pattern of excretion of markers was most conveniently studied by plotting the concentration of marker against time, or against cumulative faecal or ileal dry-matter output. Fig. I illustrates the types of curves obtained. The dominant feature common to all markers and both sections of the intestine was the rapid excretion of most of the marker once excretion had begun. With faecal excretion, however, the phase of rapid excretion was followed by an extended period during which the remainder of the marker was more slowly excreted. During this period the particulate marker (stained straw) exhibited quite a marked intermittent pattern of excretion, which was shown only slightly by the fluid marker (PEG).

The extended period of excretion did not occur when the markers were recovered from the terminal ileum. An index of this difference between small and large intestines can be obtained by comparing the mean retention time with the mean time of maximal concentration of a marker. The comparison is shown in Table 6 . Both with the small and large intestines together and with the large intestine alone, the time of maximum concentration of stained straw was consistently about $5 \mathrm{~h}$ shorter than the mean retention time. In the small intestine the times did not differ significantly. Similar results were obtained with the plastic discs and with PEG. 
Table 6. Differences $(h)$ between the mean retention time and the mean time of maximum concentration for stained straw in the intestines of three sheep

$\begin{array}{lccc}\text { Mean } & \begin{array}{c}\text { Time of } \\ \text { retention } \\ \text { time }\end{array} & \begin{array}{c}\text { maximum } \\ \text { concentration }\end{array} & \begin{array}{c}\text { Significance } \\ \text { of differencc } \\ (1-2)\end{array} \\ \text { Region of gut } & \text { (I) } & \text { (2) } & \text { Not significant } \\ \text { Small intestine } & 3.07 & 2.96 & P<0.001 \\ \text { Large intestine } & 17.6 & 12.2 & P<0.001\end{array}$
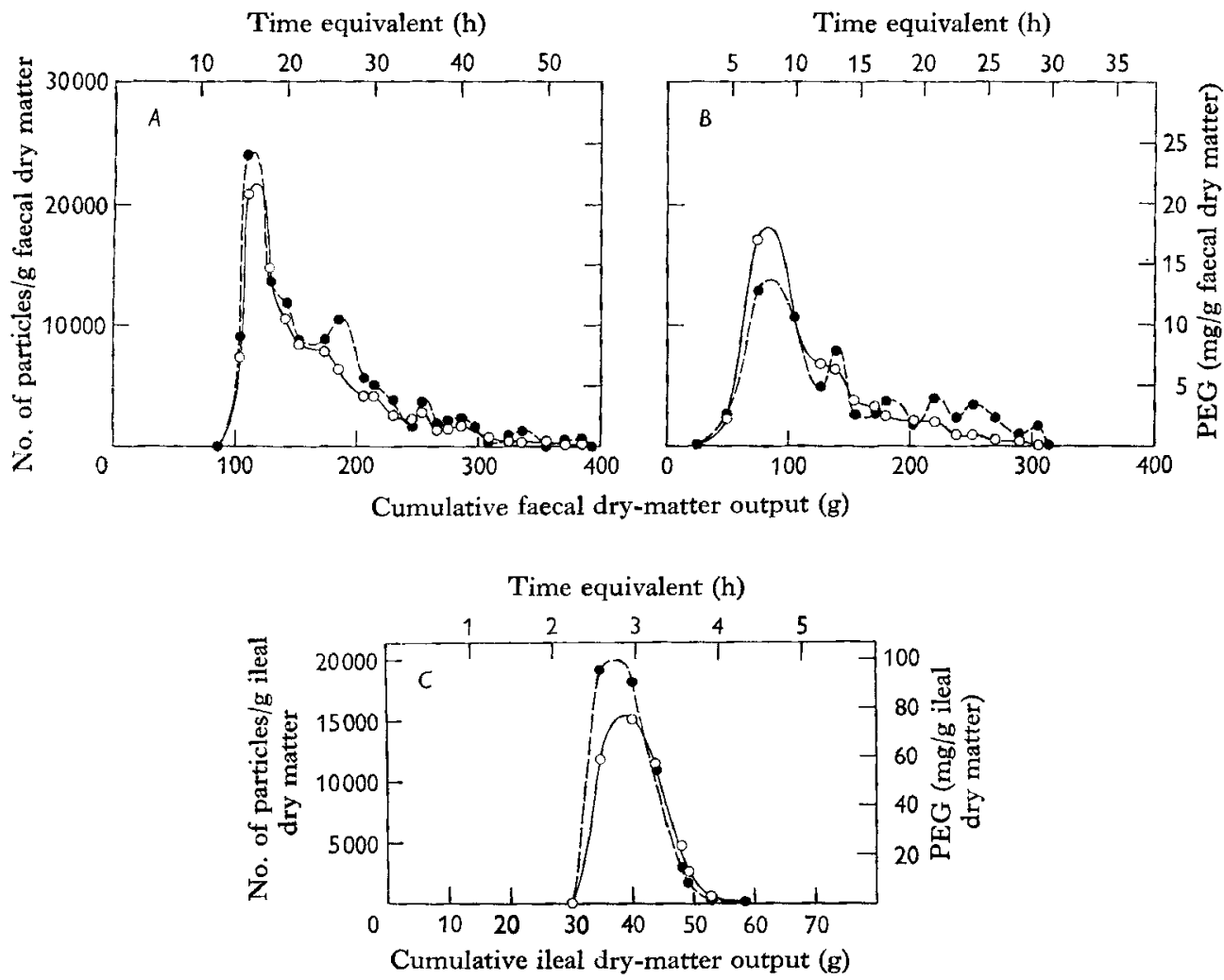

Fig. I. Patterns of excretion of stained straw particles $(\bullet---)$ and PEG $(\circ-0)$ from the intestines of sheep. $A$, small + large intestines, Alfred, $760 \mathrm{~g}$ dried grass daily; $B$, large intestine, and $C$, small intestine, Charlie, $1200 \mathrm{~g}$ dried grass daily.

\section{DISCUSSION}

A variety of methods has been used to measure the rate of passage of digesta through the gut of the ruminant. Radiography, as used by Benzie \& Phillipson (I957), provides an overall picture of the movements of digesta and of the major contractions of the gut. Some indication is also given of the rate of flow of radio-opaque material along the intestine, though this is not defined sharply enough to permit precise measurement.

The retention time of particulate matter in the gut is frequently measured by 
staining a part of the food and recovering the stained particles in the faeces. Balch (I950) has pointed out that a little of the stained food will begin to leave the reticulorumen as soon as it is eaten. Consequently, by measuring the time of retention of the first few stained particles to appear in the faeces and that of the bulk of the particles it is possible to distinguish between retention in the gut beyond the reticulo-rumen and in the reticulo-rumen itself. In practice, the times taken for excretion of the first $5 \%$ and the first $80 \%$ of recovered particles are often adopted as convenient indices, though in fact the $5 \%$ excretion time is some $3-6 \mathrm{~h}$ longer than the mean retention time of particles introduced into the abomasum of cows (Balch, 1950) or the duodenum of goats (Castle, $1956 \mathrm{~b}$ ).

An alternative approach is to slaughter animals after a marker has been given for sufficient time to permeate the whole gut. The retention time for each section of the gut is found by dividing the amount of marker in each section by the rate of administration. Hydén (I961 $a$ ) used this method with sheep, infusing PEG into the rumen as a marker, and obtained fluid retention times of $0.5^{-1} \mathrm{~h}$ for the abomasum, $\mathrm{I}-2 \mathrm{~h}$ for the small intestine, 6-I $\mathrm{h}$ for the caecum, and IO-I I h for the colon plus rectum. Our range of retention times for the large intestine corresponds well to Hydén's range for caecum, colon and rectum combined but there is a surprisingly large difference between the ranges for the small intestine. Measurements based on a slaughter technique are open to a number of objections. For example, movements of digesta may occur after death, and strictly speaking successive sections of the gut are not wholly comparable at any single time since there are diurnal patterns of flow from the reticulo-rumen (Hydén, 196 $1 b$ ) and from the abomasum (Harris \& Phillipson, 1962) which presumably influence retention times. This last point may be unimportant as the slow passage of material from the lower parts of the ileum may nullify any diurnal fluctuation that occurs in the upper parts of the alimentary tract; Castle (1956b) was unable to detect any changes in intestinal retention times between day and night periods in goats.

The direct measurement of retention times in fistulated animals avoids many of the shortcomings of other methods but has its own drawbacks. Cannulation may interfere with intestinal propulsion. However accustomed a sheep may be to the collection and return of digesta through re-entrant cannulas, flow rates into the duodenum measured in this way represent only about $88-93 \%$ of the normal (Harris \& Phillipson, I962). Our measurements of retention in the small intestine called for this procedure but since the values obtained for small intestine and large intestine taken separately agreed with those for the two sections together it seems that continued sampling at the re-entrant cannulas did not affect the results substantially. The range of times obtained for the small intestine, $2 \cdot 3-4 \cdot 5 \mathrm{~h}$, is similar to that of the small intestine transit times measured in a similar manner by Smith ( 1963$)$ in calves fed with milk $(2-5 \cdot 25 \mathrm{~h})$ or hay and cereals $(\mathrm{I} \cdot 25-4 \mathrm{~h})$.

One of the main factors determining retention time in the gut as a whole is the amount of food eaten, higher intakes being associated with lower retention times. This is shown clearly by the experiments of Castle (1956a) on goats and of Blaxter et al. (1956) and Coombe $\&$ Tribe $(1963)$ on sheep. It appears to affect cows to a lesser 
extent (Campling, Freer \& Balch, I96I). Blaxter et al. (1956) applied a mathematical treatment to their values which allowed the estimation of a delay factor, $\tau$, that was tentatively equated to intestinal retention time. For a diet of long, dried grass $\tau$ was $36 \mathrm{~h}$ at $600 \mathrm{~g}$ intake and $26 \mathrm{~h}$ at $1200 \mathrm{~g}$ intake. Our values for retention time at these two intakes of a dried grass of similar composition were much shorter, about 27 and $15 \mathrm{~h}$, respectively, so that $\tau$ seems to represent a longer delay factor than can be accounted for by intestinal retention alone. Castle $(1956 b)$ found a mean intestinal retention time of $13 \mathrm{~h}$ for goats fed with hay ad lib. and calf nuts. The much longer retention times, $18-25 \mathrm{~h}$, in our sheep on hay diets are probably explained by the restrictions placed on their intake of food.

In principle, when the food intake of a sheep is increased, the intestines can handle the greater quantity of dry matter passing into them either by increasing the concentration of dry matter, or by dilating to accept a greater volume of digesta, or by propelling a greater volume more rapidly. In fact, over a moderate range of food intakes it is the volume of intestinal digesta that varies while its dry-matter concentration remains constant (Goodall \& Kay, I965; Goodall, Kay, Phillipson \& Vowles, in preparation), and the results presented in this paper and those of previous workers point to the importance of more rapid propulsion, as shown by a decreased retention time, as the means adopted by the intestines to deal with increased volume. Nevertheless, this does not rule out a certain degree of intestinal distention, and indeed this may well be the necessary stimulus to increased propulsive motility. A subsequent paper will describe the effect of increased food intake on propulsive and non-propulsive contractions of the small intestine.

The time food residues are retained in the reticulo-rumen seems to be reduced not only by increasing the intake of food but also by increasing the digestibility of the food without altering the amount eaten. Campling et al. (196I) found that, when cows were given $\mathrm{I} O \mathrm{lb}$ of hay or about $\mathrm{I} 0 \mathrm{lb}$ of oat straw, the hay residues were retained in the gut for a shorter period than the straw residues. In later experiments (Campling, Freer $\&$ Balch, 1962) the digestibility of the straw was increased by infusing urea into the rumen, and a reduction in overall retention time was produced which was due largely to decreased retention in the reticulo-rumen. The correlation found by Coombe \& Tribe (1963) between rate of cellulose digestion and rate of passage through the reticulo-rumen may be another facet of the same relationship, though in their experiments the food intake was variable. Our results show that the opposite effect is found in the intestines, the more digestible dried grass being retained for up to $5 \mathrm{~h}$ longer than similar intakes of hay. Thus, increased digestibility and decreased food intake seem to affect intestinal retention in a similar manner, presumably because both reduce the bulk of the food residues passing through the intestines. Previous work that has touched on this point has been concerned with the interrelations of digestibility, retention time and voluntary food intake. Campling et al. (1962) and Coombe \& Tribe (1963) have shown that increased digestibility is generally associated with decreased intestinal retention time, as measured by $5 \%$ excretion times for stained food, and increased food intake. Although at first sight the association of increased digestibility with decreased retention time seems at variance with our results, the 
increased food intake may in fact have decreased retention time to an extent that obscured any opposite effect of digestibility. A more directly conflicting observation was reported by Campling et al. (I96I): stained particles introduced into the abomasum of cows were retained for a shorter time when hay was given than with a straw diet. In the later experiments in which the digestibility of straw was increased by urea, however, there was no consistent relation between digestibility and intestinal retention ( $5 \%$ excretion time) (Campling et al. 1962).

A large part of the food eaten by ruminants is digested in the compartments of the stomach and so it was thought that retention of food residues in the intestines might be influenced more by the amount of indigestible dry matter eaten than by the total food intake. However, faecal dry matter-a measure of the intake of indigestible dry matter-did not show the predominating correlation with intestinal retention time that was expected, and this point clearly needs further attention.

Three different markers were used. The polyvinyl chloride discs were easy to recover and count, and it was hoped that for measurements of intestinal retention time they might serve as a useful substitute for the more troublesome stained food particles. No significant difference was found between the retention times of the discs and the stained straw, despite the high specific gravity $(\mathrm{I} \cdot 2)$ of the discs. Only a relatively small number of discs was used, and so they gave a less smooth excretion curve than the straw. Campling \& Freer (I962) found that compact polystyrene particles were unsuitable as a retention marker for the whole gut since they were retained for a rather shorter time than stained food particles. They also showed that the time compact rubber particles were retained in the reticulo-rumen and in the remainder of the gut depended on their specific gravity, but evidently this factor is unimportant when the ratio of surface to volume is as great as in our plastic discs.

PEG, a soluble marker, was compared with the solid markers to find whether there was any difference in retention times between fluids and particulate matter. No difference was found in retention times in the small and large intestines together or in the large intestine alone, but in the small intestine PEG was retained significantly longer than stained straw. This indicates a preferential retention of fluids in the small intestine; it is difficult to explain why it should occur, if indeed the observation can be confirmed. Using radioyttrium as a marker, Marcus \& Lengemann (1962) produced some evidence that the reverse process, a preferential retention of solids, occurs in the distal jejunum of rats.

The slow excretion of the later part of the doses of markers from the large intestine and the interesting fluctuation in the concentration of stained straw during this phase suggest that passage through the large intestine involves some storing, mixing and intermittent release of the digesta over a period of at least $24 \mathrm{~h}$. On anatomical grounds the organ most likely to be concerned in this function is the caecum, which in sheep holds variable amounts of digesta, sometimes exceeding rooo g (Boyne et al. 1956).

Only the causes of variations in intestinal retention time have been considered so far. These variations may also have some important effects. First, as Campling, Freer \& Balch (1963) point out, an excessively fast flow of digesta into the intestines may distend them sufficiently to depress appetite; such a situation may sometimes 
occur with finely ground diets which tend to leave the reticulo-rumen rapidly. Second, a rapid rate of passage through the intestines-a short retention time--will set a time limit to enzymic digestion in the small intestine and to microbial fermentation in the large. It may also affect the absorption of nutrients. The positive correlation that was found between intestinal retention time and the percentage of dry matter in the faeces, more convincingly demonstrated by Castle (1956 $a, b$ ) and Blaxter et al. (1956), suggests that the efficiency with which water is absorbed from the food residues depends on the length of time they are retained in the large intestine. We have also noticed that large amounts of water and salts are excreted in the faeces an hour or so after the release of accidental blockages of ileal re-entrant cannulas. In addition, Smith ( 1963 ) has shown that the time fluid is retained in the small intestine of milkfed calves influences the absorption of magnesium, and similar considerations may apply to the absorption of other minerals.

\section{SUMMARY}

I. The retention times of digesta in the small and large intestines were studied in three sheep fitted with duodenal and re-entrant ileal cannulas. Three markers were used: small discs of polyvinyl chloride sheeting, stained particles of finely milled straw, and polyethylene glycol (PEG).

2. The markers were retained for $2 \cdot 25-4 \cdot 50 \mathrm{~h}$ in the small intestine and for $10 \cdot 2-$ $26.5 \mathrm{~h}$ in the large. In both sections of the intestine the retention times were inversely related to the dry-matter intake of a particular food, and also to faecal output. Shorter retention times were found on a hay diet than on an equal intake of more digestible dried grass.

3. PEG was retained slightly, though significantly, longer in the small intestine than stained straw. No other differences between the markers were apparent.

4. Fluctuations in the concentration of stained straw in the faeces suggest that digesta were stored and mixed to some extent in the large intestine.

We wish to thank Mr I. McDonald for advice on statistical treatments and Mr E. D. Goodall for technical assistance. The work was carried out while one of us (J.B.C.) held an Australian Dairy Produce Board Overseas Scholarship.

\section{REFERENCES}

Ash, R. W. (1962). Anim. Prod. 4, 309.

Balch, C. C. (1950). Brit. F. Nutr. 4, 361.

Benzie, D. \& Phillipson, A. T. (1957). The Alimentary Tract of the Ruminant. Edinburgh: Oliver and Boyd.

Blaxter, K. L., Graham, N. McC. \& Wainman, F. W. (1956). Brit. F. Nutr. 10, 69.

Boyne, A. W., Campbell, R. M., Davidson, J. \& Cuthbertson, D. P. (1956). Brit. J. Nutr. ro, 325.

Campling, R. C. \& Freer, M. (1962). Brit. $尹$. Nutr. I6, 507.

Campling, R. C., Freer, M. \& Balch, C. C. (196r). Brit. F. Nutr. 15, 53 r.

Campling, R. C., Freer, M. \& Balch, C. C. (1962). Brit. F. Nutr. 16, I 5.

Campling, R. C., Freer, M. \& Balch, C. C. (1963). Brit. F. Nutr. 17, 263.

Castle, E. J. (1956a). Brit. F. Nutr. ro, 15.

Castle, E. J. (1956b). Brit. F. Nutr. ro, 338 .

Coombe, J. B. \& Tribe, D. E. (1963). Aust. F. agric. Res. 14, 70. 
Duthie, I. F. (1959). Lab. Pract. 8, 408.

Goodall, E. D. \& Kay, R. N. B. (1965). F. Physiol. 176, г2.

Harris, L. E. \& Phillipson, A. T. (1962). Anim. Prod. 4, 97.

Hogan, J. P. \& Phillipson, A. T. (1960). Brit. F. Nutr. 14, 47.

Hydên, S. (1955). Kungl. LantbrHögsk. Ann. 22, 139.

Hydén, S. (1961 a). In Digestive Physiology and Nutrition of the Ruminant. Chapter 4. [D. Lewis, editor.] London: Butterworths.

Hydén, S. (196I b). Kungl. LantbrHögsk. Ann. 27, 51 .

Marcus, C. S. \& Lengemann, F. W. (1962). F. Nutr. 76, 179.

Smith, R. H. (1962). Biochem. F. 83, I 5 r.

Smith, R. H. (1963). Nature, Lond., r98, I6r.

Snedecor, G. W. (I95ó). Statistical Methods, 5th ed. Ames, Iowa: Iowa State College Press.

van Weerden, E. J. (1961). F. agric. Sci. 56, 317. 